\title{
Compact Antenna with Frequency Reconfigurability for GPS/LTE/WWAN Mobile Handset Applications
}

\author{
Lingsheng Yang, ${ }^{1}$ Biyu Cheng, ${ }^{1}$ Yongan $\mathrm{Zhu},{ }^{1}$ and Yajie $\mathrm{Li}^{2}$ \\ ${ }^{1}$ Jiangsu Key Laboratory of Meteorological Observation and Information Processing and Research Center of Applied Electromagnetics \\ of NUIST, Nanjing University of Information Science \& Technology, Ningliu Road, Nanjing 210044, China \\ ${ }^{2}$ Zhongda Hospital, Southeast University, Dingjiaqiao, Nanjing 210009, China
}

Correspondence should be addressed to Lingsheng Yang; ylsinchina@163.com

Received 12 September 2016; Revised 8 November 2016; Accepted 22 November 2016

Academic Editor: Paolo Burghignoli

Copyright (C) 2016 Lingsheng Yang et al. This is an open access article distributed under the Creative Commons Attribution License, which permits unrestricted use, distribution, and reproduction in any medium, provided the original work is properly cited.

\begin{abstract}
A compact frequency reconfigurable antenna for mobile handset application is proposed in this paper. The antenna consists of an inverted L-shaped feeding strip, a shorter grounded strip, and a longer grounded strip which is connected with four inductors by using a single-pole four-throw RF switch. When we change the working states of the RF switch, the corresponding inductor is connected with the long grounded strip and different resonant modes of the antenna can be realized. The measured $-6 \mathrm{~dB}$ impedance bandwidth of the presented antenna is $683-960 \mathrm{MHz}$ and $1460-2820 \mathrm{MHz}$, which is able to cover the LTE700/GSM850/900 and GPS/DCS1800/PCS1900/UMTS2100/LTE2300/2500 bands. The antenna gain, radiation efficiency, and radiation patterns are also described in the paper.
\end{abstract}

\section{Introduction}

With the rapid development of wireless communication, more and more wireless applications like the Wireless Wide Area Network (WWAN), Long Term Evolution (LTE), and Global Positioning System (GPS) have been developed. The antenna for mobile handset requires the integration of as many applications as possible [1]. However, the space left for antenna is highly constrained, which makes antenna design a challenge task [2-4].

Frequency reconfiguration of antenna is a powerful method for solving this problem [5]. Recently, many kinds of reconfigurable antennas have been reported [6-13]. In [6], the authors use PIN diodes to control the antenna operating modes. The antenna can cover the GSM900 band in PIFA mode and the GSM1800/GSM1900/UMTS bands in loop mode. However, the LTE700 band and LTE2300/2500 bands are not taken into consideration. A folded coupledfed reconfigurable narrow-frame antenna is presented in [7]. In order to obtain wide bandwidth in the lower band, PIN diode is inserted in the strip to generate different resonant modes; however, the antenna cannot cover the LTE700 band either. A PIFA with a PIN diode for frequency reconfigurable operation is proposed in [8]. The antenna has a simple structure and can cover the LTE700 bands; however, it has a relatively large dimension and does not include the LTE2300/2500 bands.

In order to cover all the LTE/WWAN operation bands (cover a bandwidth of $698-960 \mathrm{MHz}$ and $1710-2690 \mathrm{MHz}$ ), many efforts have been made [9-13]. Antenna connected PIN diode with simple geometry and relatively increased size is proposed in [9]. In [10], the authors proposed multimode reconfigurable antennas by changing the bias states of PIN diode to control the coupling between strips and adjust the fundamental resonant frequency, while in [11] six different resonant pathways are obtained by adjusting the bias states of two PIN diodes. With embedded circuit elements and passive reconfigurable technique, triple-wide-band can be realized in [12]. Antenna for LTE/WWAN tablet computer applications can be realized when RF switch is used to change the resonant modes of lower band among different working states [13].

In this paper, a compact frequency reconfigurable antenna is proposed for mobile handset applications. The antenna has a dimension of $12 \times 28 \mathrm{~mm}^{2}$ which is smaller than 
TABLE 1: Size and performance of previously reported antennas and the proposed antenna.

\begin{tabular}{|c|c|c|c|c|c|c|}
\hline Number & Size $\left(\mathrm{mm}^{2}\right)$ & Efficiency & Gain $(\mathrm{dBi})$ & $\begin{array}{c}\text { Achieved bandwidth } \\
(\mathrm{MHz})\end{array}$ & Relative bandwidth & Reconfigurability cost \\
\hline [9] & $15 \times 60$ & $>70 \% />60 \%$ & $2 \sim 2.5 / 4.2 \sim 5$ & 698 960/1710 2690 & $31.6 \% / 44.5 \%$ & PIN diode \\
\hline [11] & $10 \times 36.5$ & $>52.83 \% />52.14 \%$ & $0.13 \sim 1.59 / 0.68 \sim 3.85$ & 698 960/1710 2690 & $31.6 \% / 44.5 \%$ & PIN diode \\
\hline [13] & $12 \times 40$ & $>50 \% />50 \%$ & $1 \sim 3 / 2 \sim 4$ & 698 960/1710 2690 & $31.6 \% / 44.5 \%$ & $\begin{array}{c}\text { RF switch and } \\
\text { lumped inductances }\end{array}$ \\
\hline Proposed antenna & $12 \times 28$ & $>50 \% />60 \%$ & $-1.43 \sim 2.28 / 0.42 \sim 2.0$ & 683 960/1460 2820 & $33.7 \% / 63.6 \%$ & $\begin{array}{c}\text { RF switch and } \\
\text { lumped inductances }\end{array}$ \\
\hline
\end{tabular}

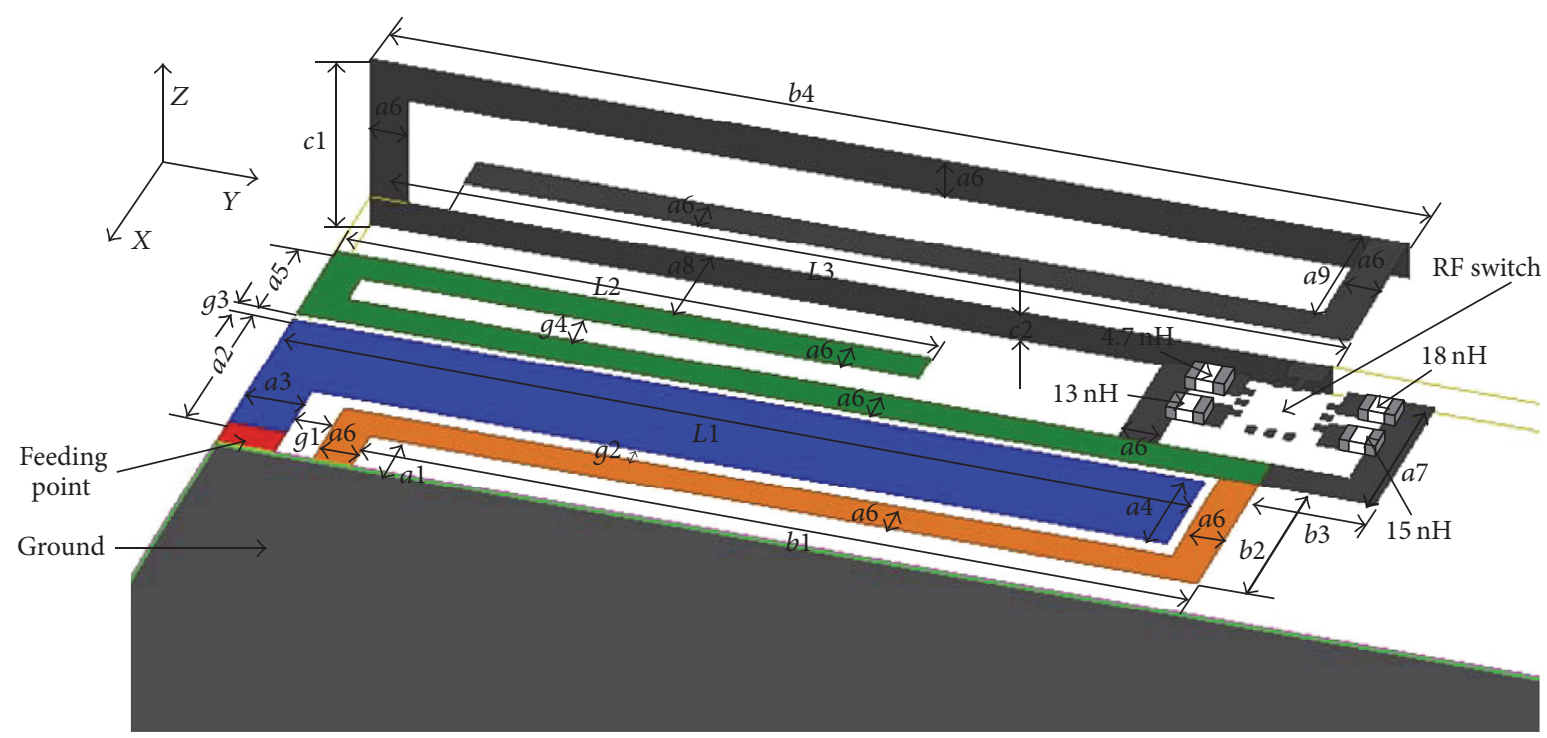

(a)

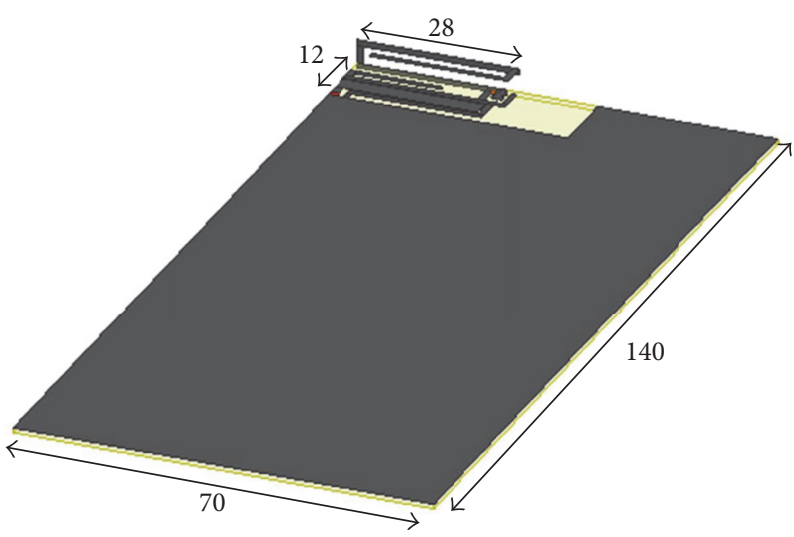

(b)

FIGURE 1: Geometry of the proposed antenna. (a) Detailed dimensions. (b) Overall structure.

most of the previous designs (see some of the comparison in Table 1). Under the $-6 \mathrm{~dB}$ impedance matching criterion, the proposed antenna has wider bandwidth in both lower and upper gigahertz bands, which means the antenna can integrate more wireless applications simultaneously within a more compact size. Meanwhile, the gain and efficiency performances show the antenna has acceptable performances through the whole GPS, WWAN, and LTE bands.

\section{Antenna Design}

The proposed antenna is placed on a $0.8 \mathrm{~mm}$ thick FR4 dielectric substrate with a permittivity of 4.4 and a loss tangent of 0.02 . The flat area of the board is $140 \times 70 \mathrm{~mm}^{2}$ which stands for a typical 5.5-inch smart phone. As shown in Figure 1, the radiating part of the antenna consists of an inverted L-shaped feeding strip and two coupling fed 
TABLE 2: The parameters of the proposed antenna.

\begin{tabular}{lc}
\hline Parameter & Value $(\mathrm{mm})$ \\
\hline$a 1$ & 1.5 \\
$a 2$ & 5 \\
$a 3$ & 1.5 \\
$a 4$ & 3 \\
$a 5$ & 3 \\
$a 6$ & 1 \\
$a 7$ & 3.7 \\
$a 8$ & 2.7 \\
$a 9$ & 3.7 \\
$b 1$ & 21.5 \\
$b 2$ & 4.8 \\
$b 3$ & 3 \\
$b 4$ & 28 \\
$L 1$ & 23.7 \\
$L 2$ & 14.5 \\
$L 3$ & 22 \\
$g 1$ & 1 \\
$g 2$ & 0.5 \\
$g 3$ & 0.3 \\
$g 4$ & 1 \\
$c 1$ & 4.8 \\
$c 2$ & 0.8 \\
\hline
\end{tabular}

TABLE 3: The states of RF switch and operating bands.

\begin{tabular}{lcccc}
\hline States & V1 & V2 & $\begin{array}{c}\text { Output } \\
\text { inductor }\end{array}$ & Operating bands \\
\hline 1 & Low & Low & $4.7 \mathrm{nH}$ & $792-960 \mathrm{MHz} / 1485-2820 \mathrm{MHz}$ \\
2 & High & Low & $13 \mathrm{nH}$ & $749-793 \mathrm{MHz} / 1460-2720 \mathrm{MHz}$ \\
3 & Low & High & $15 \mathrm{nH}$ & $717-760 \mathrm{MHz} / 1480-2680 \mathrm{MHz}$ \\
4 & High & High & $18 \mathrm{nH}$ & $683-720 \mathrm{MHz} / 1460-2620 \mathrm{MHz}$ \\
\hline
\end{tabular}

grounded strips. The inverted L-shaped feeding strip (blue) and the shorter grounded strip (orange and green) are printed on the upper layer of the substrate, while the longer grounded strip (orange and black) is folded with a height of $4 \mathrm{~mm}$ upon the substrate after going through a single-pole four-throw RF switch (RF1604). The switch is used to connect the inductors and the longer grounded strip. Detailed size of the proposed antenna is described in Table 2, and the schematic of the RF switch is shown in Figure 2.

The connection states of the four lumped inductors are controlled by the bias voltages on the two ports of the switch as (V1, V2). For one state of the RF switch, only one lumped inductor is connected. The states of the RF switch and the relevant operating bands can be found in Table 3. In the lower band the resonance frequencies decrease with the increase of the inductance. By using frequency reconfiguration, the proposed antenna can cover a lower band of $683-960 \mathrm{MHz}$ and an upper band

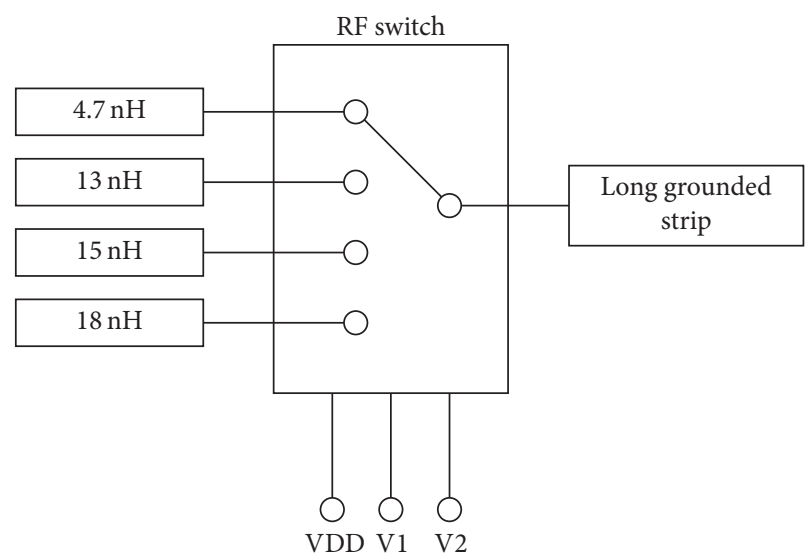

FIGURE 2: RF switch schematic diagram.

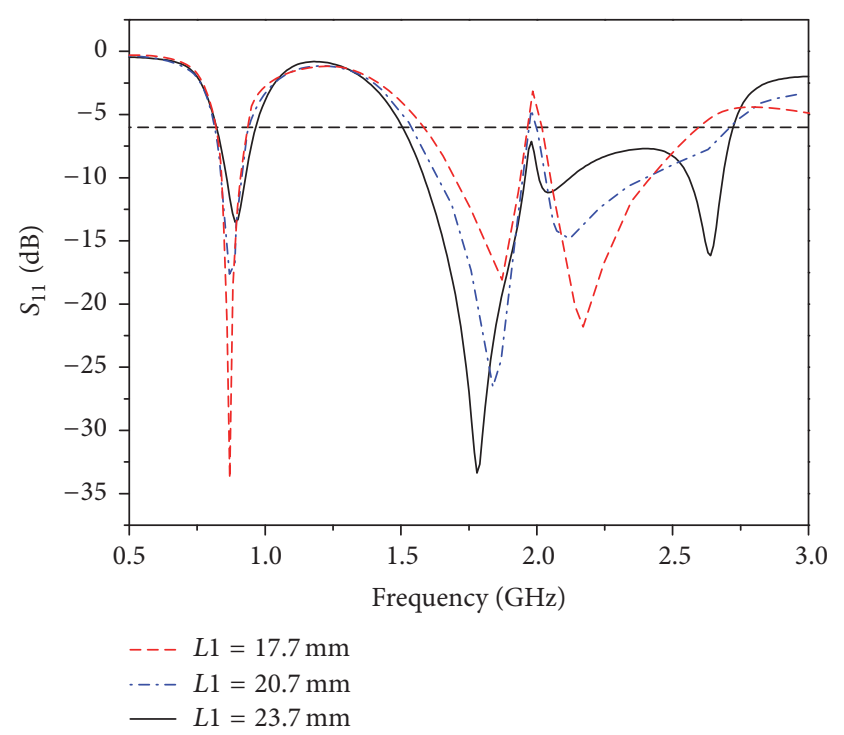

FIGURE 3: Reflection coefficient of the proposed antenna for different value of $L 1$.

of $1460-2820 \mathrm{MHz}$, including LTE700/GSM850/900 and GPS/DCS1800/PCS1900/UMTS2100/LTE2300/2500 bands for mobile phone applications.

For the proposed antenna, the inverted L-shaped feeding strip not only couples the energy to the grounded strips but also realizes the first high resonant frequency in the upper band at around $1780 \mathrm{MHz}$. From Figure 3, it can be observed that increasing the length of the inverted L-shaped strip lowers the first resonance frequency in the upper band. Other resonance frequencies in the upper band are also affected due to the coupling effects between the L-shaped strip and grounded strips.

The shorter grounded strip mainly affects the second resonant frequency in the upper band at about $2040 \mathrm{MHz}$. Figure 4 shows the reflection coefficients of the proposed antenna with different value of $L 2$. It can be observed that 


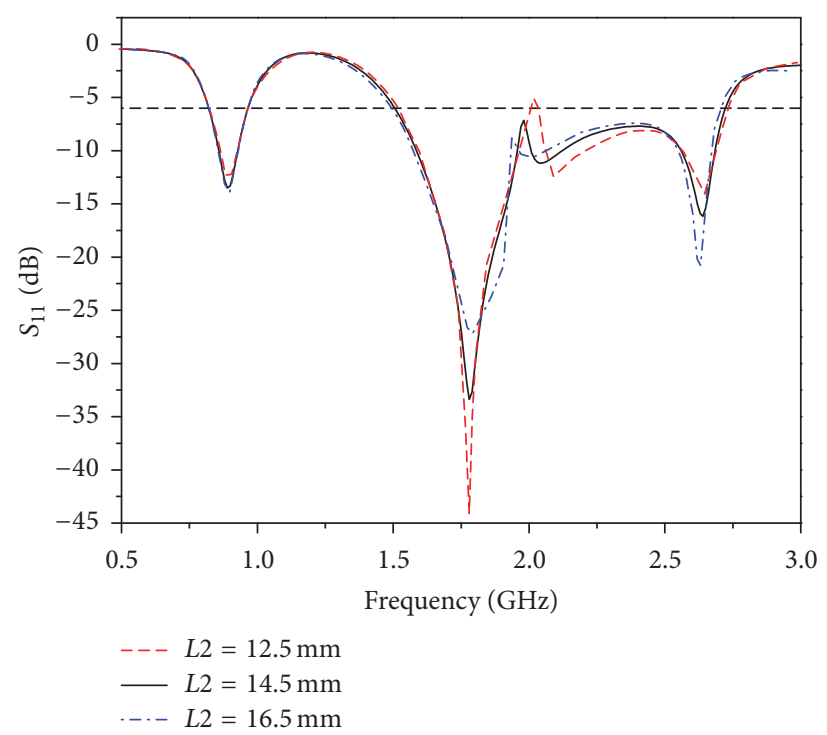

FIGURE 4: Reflection coefficient of the proposed antenna for different value of $L 2$.

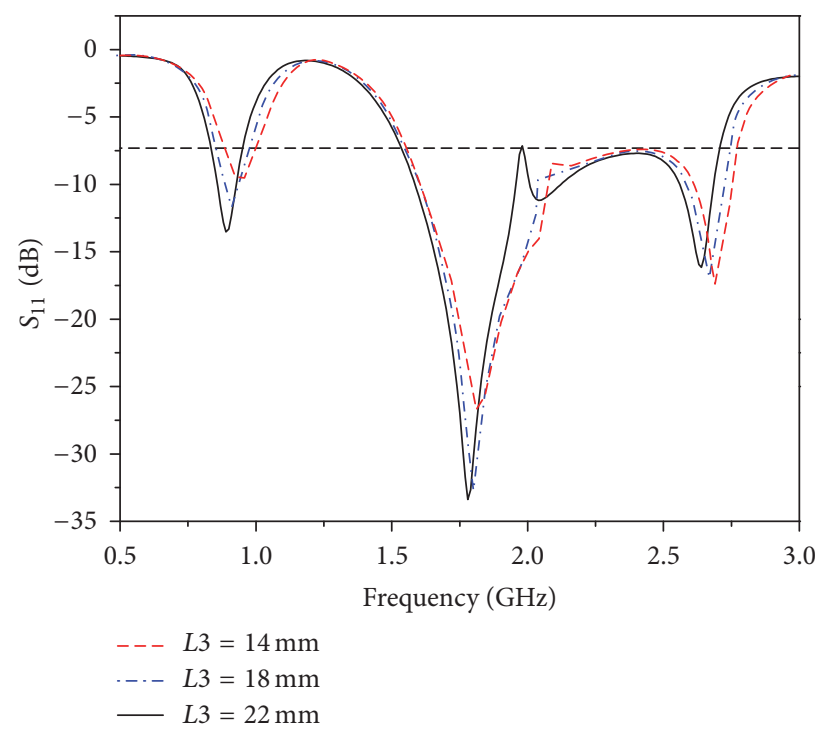

FIGURE 5: Reflection coefficient of the proposed antenna for different value of $L 3$.

the second high resonance frequency will decrease while $L 2$ becomes longer. When the second high resonance frequency becomes close to the first one, the antenna will achieve a wide impedance matching band.

The longer grounded strip connected with lumped inductors is responsible for the resonant frequencies in the lower band, the third high resonant frequency in the upper band. Meanwhile, the coupling with shorter grounded strip will also have a certain effect on the second high resonant frequency. Taking the case of connecting the $4.7 \mathrm{nH}$ inductor, for example, as shown in Figure 5, the change of $L 3$ affects the lower band resonance frequency and the second and third high resonant frequencies.

The simulated surface current distributions of the antenna on state 1 (connecting the $4.7 \mathrm{nH}$ inductor) at
$900 \mathrm{MHz}, 1780 \mathrm{MHz}, 2040 \mathrm{MHz}$, and $2640 \mathrm{MHz}$ are shown in Figure 6, respectively. In Figure 6(a), it can be found that the current flows along the long grounded strip and the path length is nearly half wavelength at $900 \mathrm{MHz}$. As shown in Figure 6(b), when the antenna resonant frequency is at $1780 \mathrm{MHz}$, the surface currents mainly concentrate in the feeding L-shaped strip. In Figure 6(c), coupled currents flow on both the shorter and longer grounded strips, while in Figure 6(d) stronger currents flow in longer grounded strips.

\section{Results and Discussion}

The photos of the fabricated antenna are shown in Figure 7. The ground and the strips on the top layer of the board are 

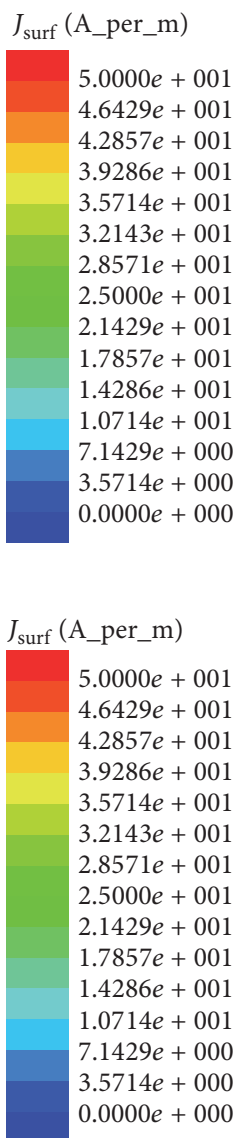

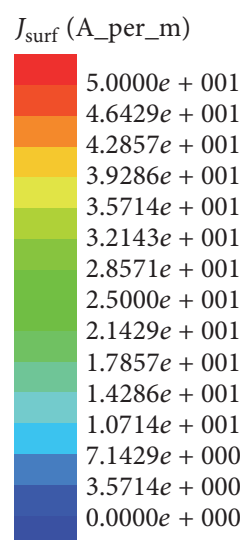

(a)

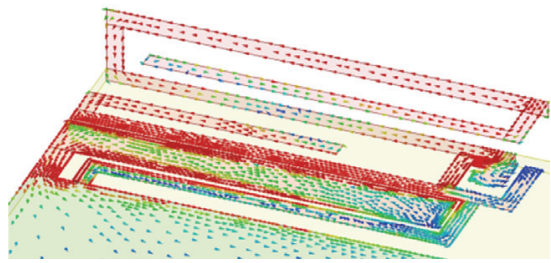

(c)

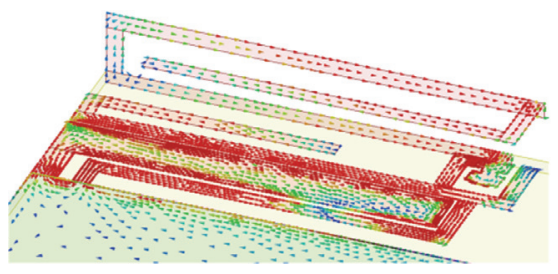

(b)

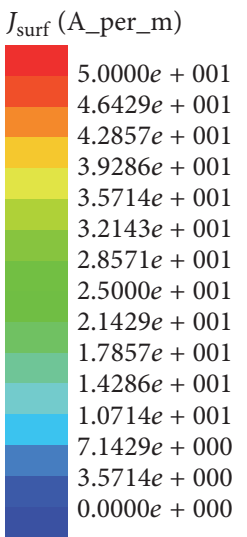

$0.0000 e+000$

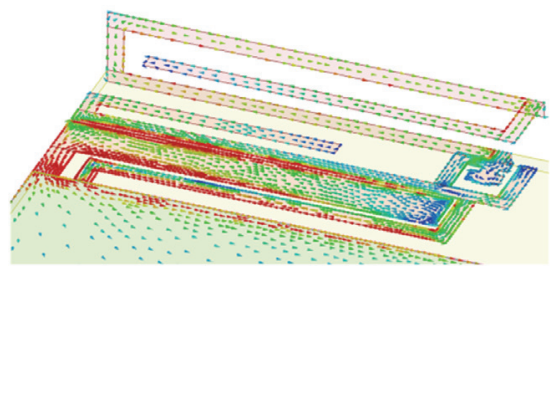

(d)

Figure 6: Simulated surface current distributions of antenna 1 at (a) $900 \mathrm{MHz}$, (b) $1780 \mathrm{MHz}$, (c) $2040 \mathrm{MHz}$, and (d) $2640 \mathrm{MHz}$.
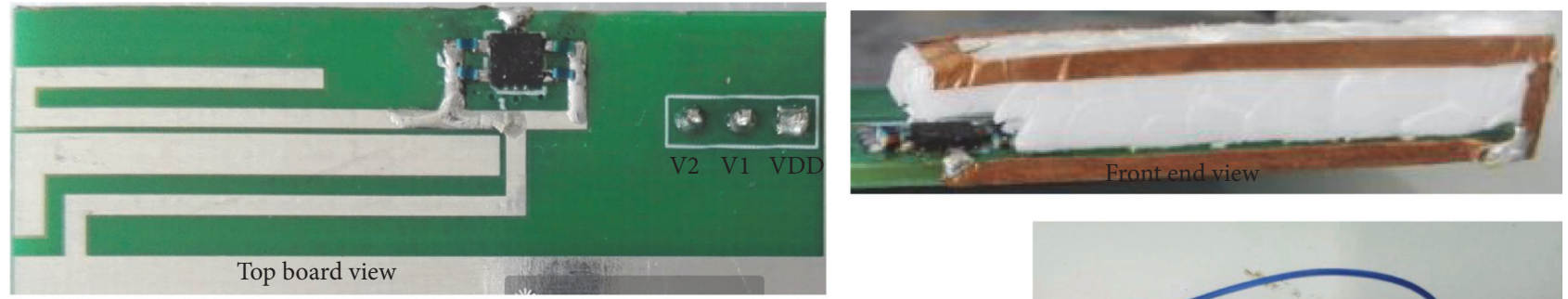

Top board view


Figure 7: Photos of the fabricated antenna. 


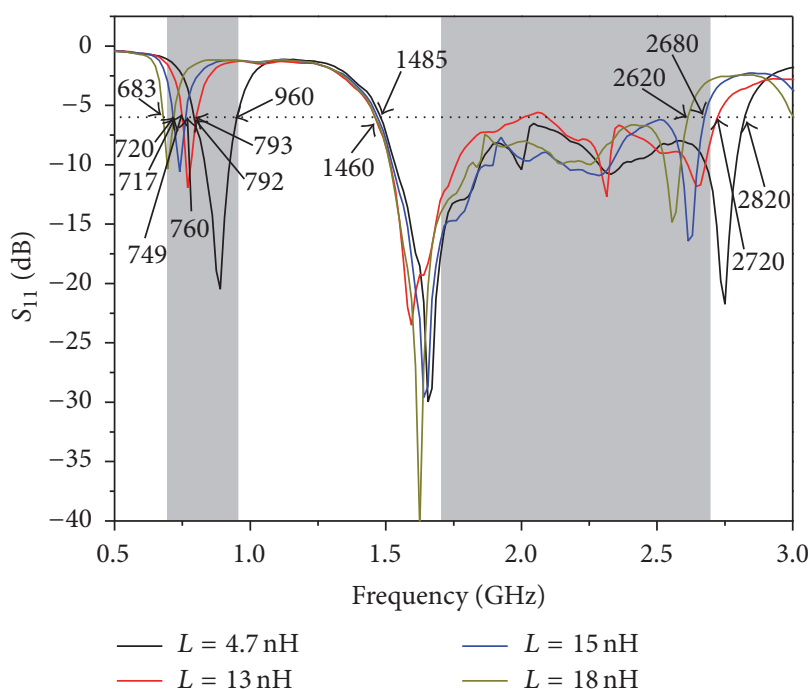

(a)

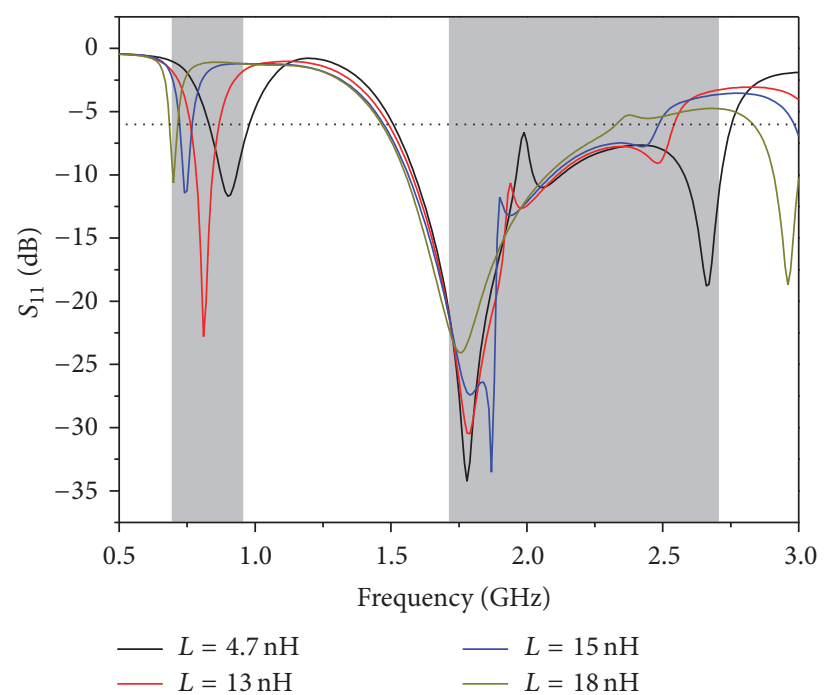

(b)

FIGURE 8: Measured (a) and simulated (b) reflection coefficients for the proposed antenna against frequency.

copper with tin coating. The foam is used to support the suspended copper strips during the measurement. On the bottom of the board, the "high" bias voltages on the two ports V1 and V2 are controlled by two AA batteries (placed in the black box), and the "low" bias voltages on the two ports V1 and V2 are controlled by the controlling lines connected to the GND. The voltage on port VDD is also connected to the GND. By changing the voltage level on ports V1 and V2 (in this paper, we change the inserting states of the wire pin in the circuit board), different states of the RF switch can be achieved.

The measured and simulated reflection coefficients are plotted in Figure 8. According to the results, for state 1, when $4.7 \mathrm{nH}$ inductor is connected with the long grounded strip, the $-6 \mathrm{~dB}$ measured impedance bandwidth can cover $792-960 \mathrm{MHz}$ and $1485-2820 \mathrm{MHz}$. For state 2, when $13 \mathrm{nH}$ inductor is connected, the measured $-6 \mathrm{~dB}$ impedance bandwidth is $749-793 \mathrm{MHz}$ and $1460-2720 \mathrm{MHz}$. For state 3, when $15 \mathrm{nH}$ inductor is connected, the measured $-6 \mathrm{~dB}$ impedance bandwidth is $717-760 \mathrm{MHz}$ and $1485-2680 \mathrm{MHz}$. For state 4 , when $18 \mathrm{nH}$ inductor is connected, the measured $-6 \mathrm{~dB}$ impedance bandwidth can cover $683-720 \mathrm{MHz}$ and $1460-$ $2620 \mathrm{MHz}$. The changes of states affect the lower frequency bands. This is because the inductors are connected with the longer grounded strip which controls the resonant modes of the lower band. Highest resonant frequency in the upper band is also affected; this is because the coupling between the two grounded strips is changed with different inductors. The differences between the measured and simulated results are mainly caused by the fabricating error and the change of the characteristics of the board and lumped elements according to the change of frequencies.

Figure 9 shows the measured and simulated normalized radiation pattern when the antenna operates at $900 \mathrm{MHz}$, $1900 \mathrm{MHz}$, and $2450 \mathrm{MHz}$, respectively. At $900 \mathrm{MHz}$, dipolelike radiation patterns can be observed, and for frequencies in the upper bands like $2450 \mathrm{MHz}$ more nulls can be observed because of the higher-order mode of the antenna.

The gain and radiation efficiency of the antenna are shown in Figure 10. In the lower band (683-960 MHz), the measured gain varies from $-1.43 \mathrm{dBi}$ to $2.28 \mathrm{dBi}$, while in the upper band (1460-2820 MHz) the measured gain varies from $0.42 \mathrm{dBi}$ to $2.0 \mathrm{dBi}$. The radiation efficiency of the proposed antenna is greater than $50 \%$ in the lower band and greater than $60 \%$ in the upper band, which is acceptable for mobile handset application [9].

\section{Conclusion}

A compact antenna for mobile handset application was proposed. By simply changing the working states of RF switch, frequency reconfigurable performances can be fulfilled. With a size of $12 \times 28 \mathrm{~mm}^{2}$, the antenna can cover LTE700/GSM850/900 and GPS/DCS1800/PCS1900/ UMTS2100/LTE2300/2500 bands. The measured gain, radiation efficiency, and other characteristics show the proposed antenna is competitive for multiband mobile handset applications.

\section{Competing Interests}

The authors declare that there is no conflict of interests regarding the publication of this paper.

\section{Acknowledgments}

This work was supported in part by the Natural Science Foundation of China (no. 41401572), Priority Academic Program Development of Jiangsu Higher Education Institutions (PAPD) and Jiangsu Innovation \& Entrepreneurship Group 

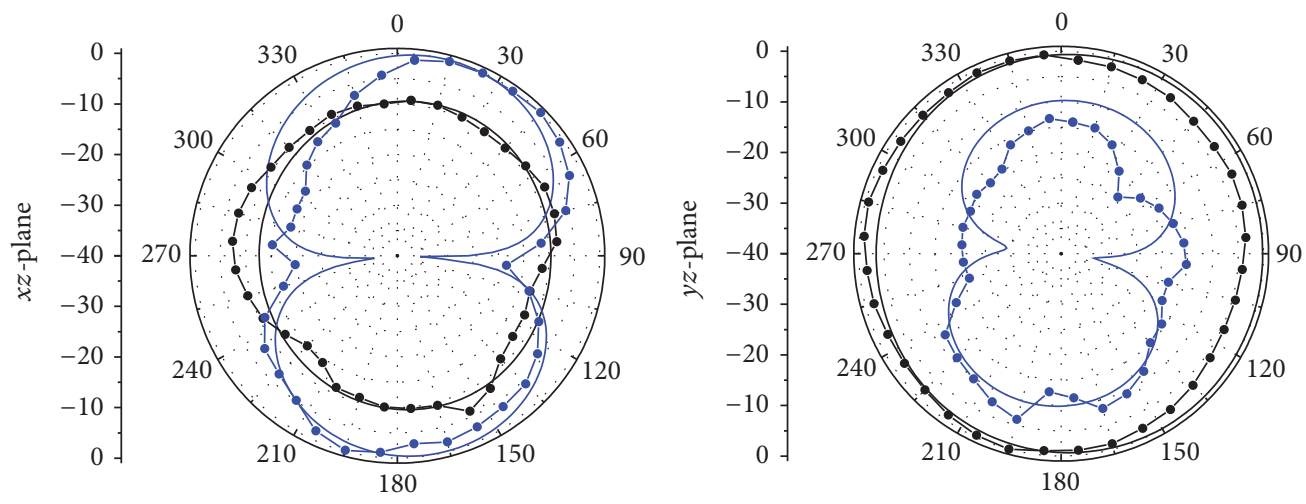

$\longrightarrow E_{\varphi}$ (simulated) $\longrightarrow E_{\theta}$ (simulated)

$\begin{array}{ll}\left.E_{\varphi} \text { (simulated }\right) & -E_{\theta} \text { (simulated) } \\ -\bullet & E_{\varphi} \text { (measured) }\end{array}-E_{\theta}$ (measured)

(a)
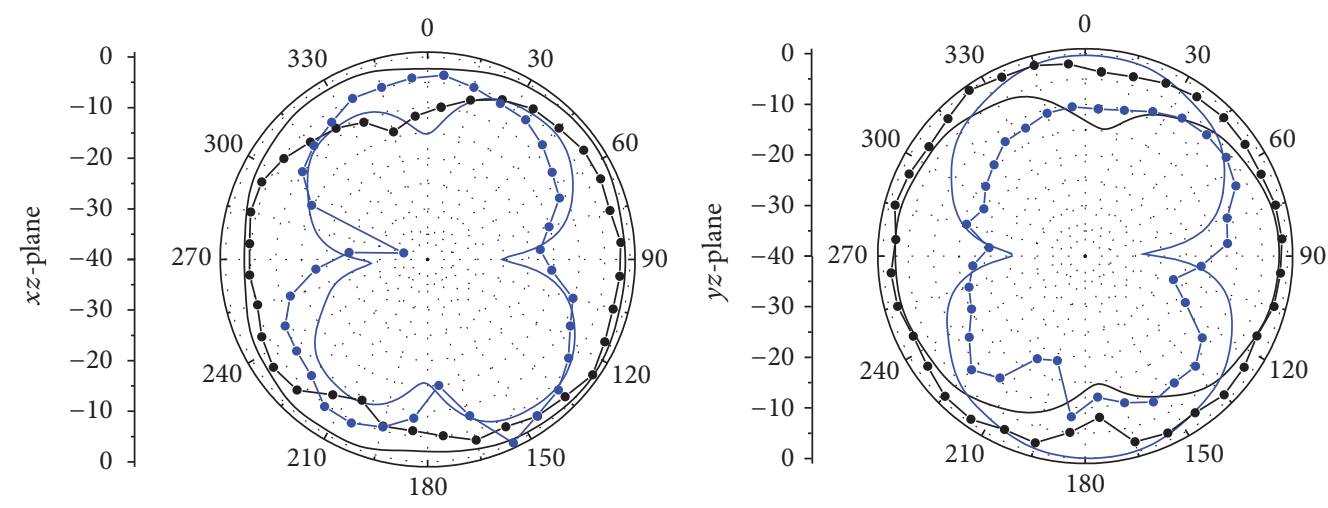

$-E_{\varphi}$ (simulated) $\quad-E_{\theta}$ (simulated)
$--E_{\varphi}$ (measured)

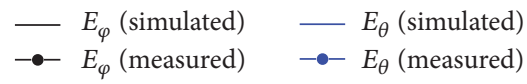

(b)
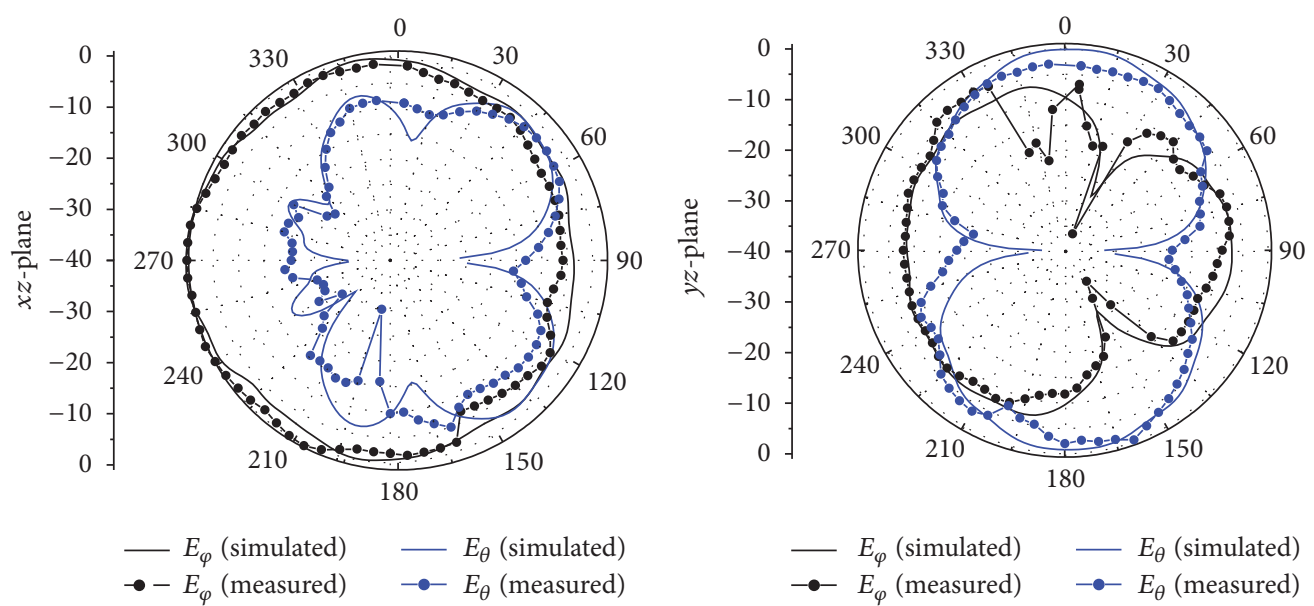

(c)

FIGURE 9: Measured and simulated radiation patterns for the proposed antenna: at (a) $900 \mathrm{MHz}$, (b) $1900 \mathrm{MHz}$, and (c) $2450 \mathrm{MHz}$. 


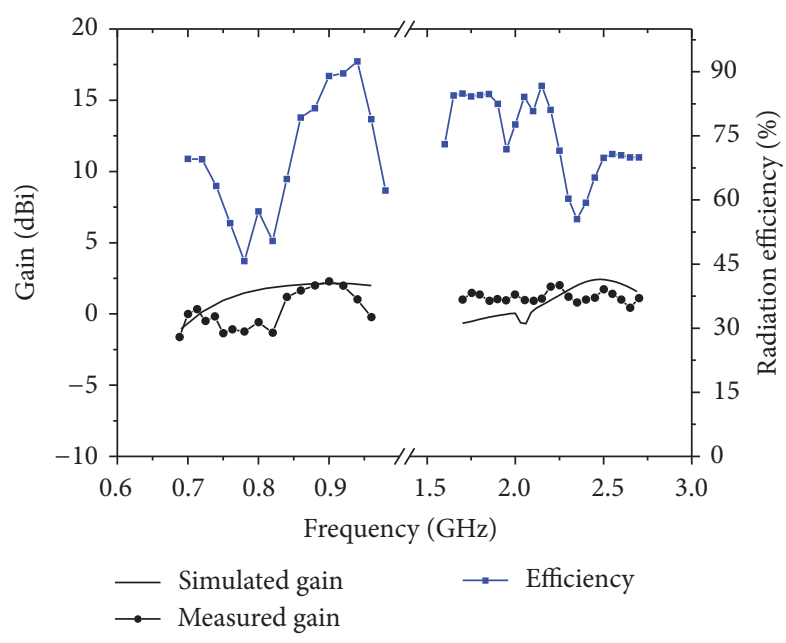

FIgURE 10: Antenna gain and radiation efficiency.

Talents Plan, and the Postgraduate Innovation Project of Jiangsu Province.

\section{References}

[1] B.-Y. Park, M.-H. Jeong, and S.-O. Park, "A magneto-dielectric handset antenna for LTE/WWAN/GPS applications," IEEE Antennas and Wireless Propagation Letters, vol. 13, pp. 14821485, 2014.

[2] Y.-L. Ban, J.-H. Chen, J. L.-W. Li, and Y. Wu, "Small-size printed coupled-fed antenna for eight-band LTE/GSM/UMTS wireless wide area network operation in an internal mobile handset," IET Microwaves, Antennas and Propagation, vol. 7, no. 6, pp. 399407, 2013.

[3] D.-B. Lin, J.-H. Chou, S.-O. Fu, and H.-J. Li, "A compact dualband printed antenna design for LTE operation in handheld device applications," International Journal of Antennas and Propagation, vol. 2014, Article ID 897328, 9 pages, 2014.

[4] Y. Hong, J. Tak, J. Baek, B. Myeong, and J. Choi, "Design of a multiband antenna for LTE/GSM/UMTS band operation," International Journal of Antennas and Propagation, vol. 2014, Article ID 548160, 9 pages, 2014.

[5] J. Costantine, Y. Tawk, S. E. Barbin, and C. G. Christodoulou, "Reconfigurable antennas: design and applications," Proceedings of the IEEE, vol. 103, no. 3, pp. 424-437, 2015.

[6] Y.-K. Park and Y. Sung, "A reconfigurable antenna for quadband mobile handset applications," IEEE Transactions on Antennas and Propagation, vol. 60, no. 6, pp. 3003-3006, 2012.

[7] Y.-L. Ban, Z. X. Chen, Z. Chen, K. Kang, and J. L.-W. Li, "Reconfigurable narrow-frame antenna for heptaband WWAN/LTE smartphone applications," IEEE Antennas and Wireless Propagation Letters, vol. 13, pp. 1365-1368, 2014.

[8] J. H. Lee and Y. Sung, "Reconfigurable hexa-band planar inverted-F antenna using a PIN diode for mobile handset," Microwave and Optical Technology Letters, vol. 55, no. 8, pp. 1926-1928, 2013.

[9] B. Bhellar and F.-A. Tahir, "Frequency reconfigurable antenna for hand-held wireless devices," IET Microwaves, Antennas \& Propagation, vol. 9, no. 13, pp. 1412-1417, 2015.
[10] S. W. Lee, H. S. Jung, and Y. J. Sung, "A reconfigurable antenna for LTE/WWAN mobile handset applications," IEEE Antennas and Wireless Propagation Letters, vol. 14, pp. 48-51, 2015.

[11] S. W. Lee and Y. Sung, "Compact frequency reconfigurable antenna for LTE/WWAN mobile handset applications," IEEE Transactions on Antennas and Propagation, vol. 63, no. 10, pp. 4572-4577, 2015.

[12] K.-L. Wong and Z.-G. Liao, "Passive reconfigurable triplewideband antenna for LTE tablet computer," IEEE Transactions on Antennas and Propagation, vol. 63, no. 3, pp. 901-908, 2015.

[13] Y.-L. Ban, S.-C. Sun, P.-P. Li, J. L.-W. Li, and K. Kang, "Compact eight-band frequency reconfigurable antenna for LTE/WWAN tablet computer applications," IEEE Transactions on Antennas and Propagation, vol. 62, no. 1, pp. 471-475, 2014. 


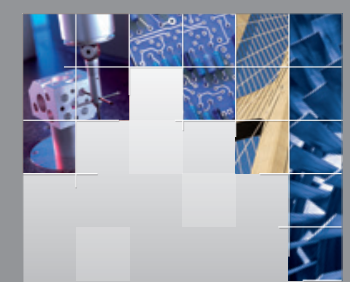

\section{Enfincering}
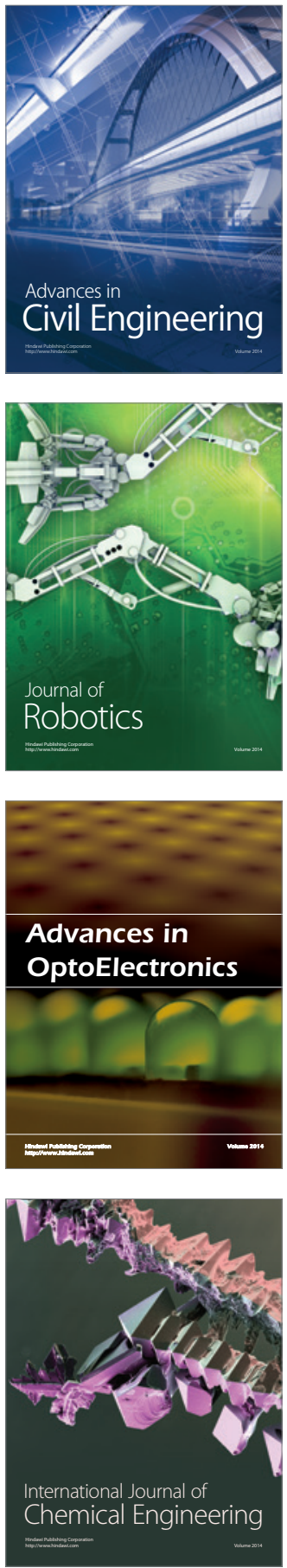

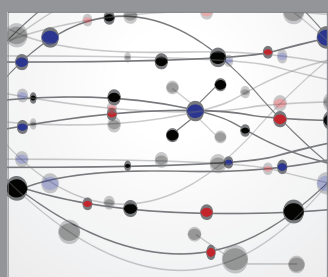

The Scientific World Journal

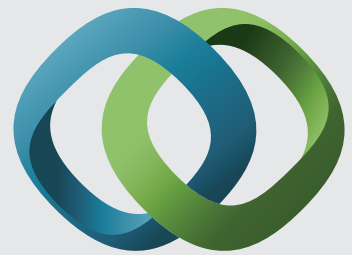

\section{Hindawi}

Submit your manuscripts at

http://www.hindawi.com
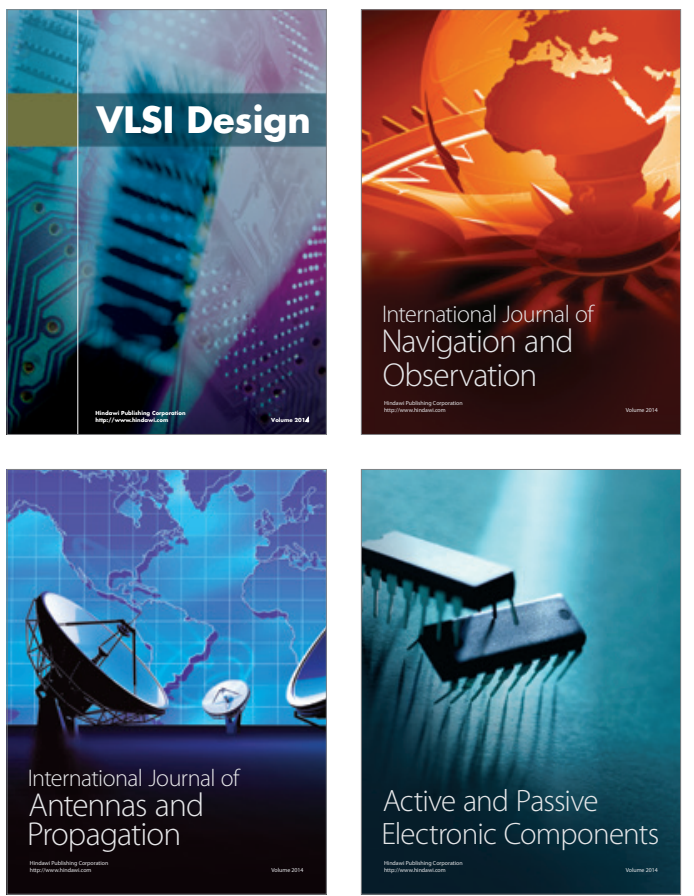


International Journal of

Distributed

Sensor Networks

Journal of

Control Science

and Engineering
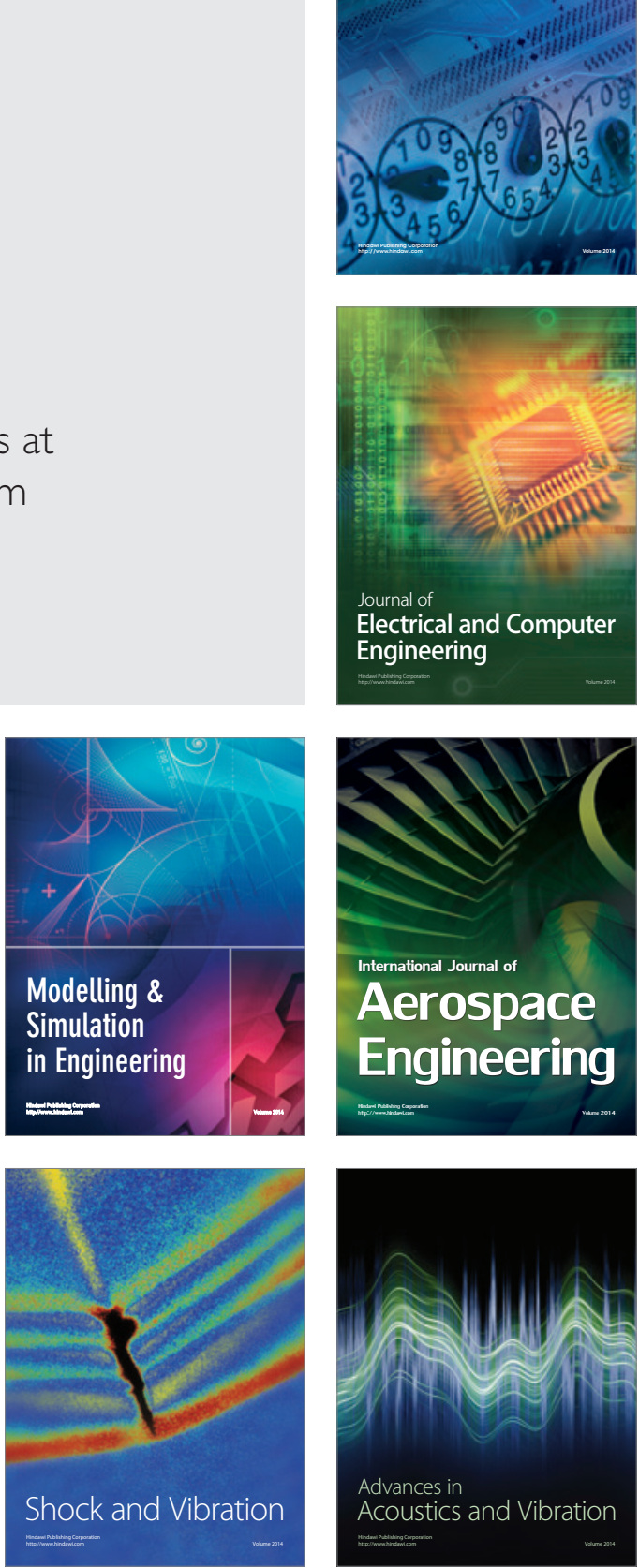